Carolina Garcia-Vidal ${ }^{*}$

Fernanda Meira ${ }^{*}$

Alberto Cózar-Llistó

Gerard Dueñas ${ }^{1}$

Pedro Puerta-Alcalde ${ }^{1}$

Nicole Garcia-Pouton'

Mariana Chumbita'

Celia Cardozo ${ }^{1}$

Marta Hernandez-Meneses ${ }^{1}$

Rodrigo Alonso-Navarro'

Verónica Rico ${ }^{1}$

Daiana Agüero'

Marta Bodro'

Laura Morata ${ }^{1}$

Carlota Jordan'

Carlos Lopera'

Juan Ambrosioni ${ }^{1}$

Ferran Segui ${ }^{1}$

Nacho Grafia ${ }^{1}$

Pedro Castro ${ }^{2}$

Felipe Garcia'

Josep Mensa'

José Antonio Martínez'

Gemma Sanjuan ${ }^{1,3}$

Alex Soriano ${ }^{1}$

and COVID19-researcher

group.

\section{Real-life use of remdesivir in hospitalized patients with COVID-19}

${ }^{1}$ Department of Infectious Diseases, Hospital Clinic of Barcelona-IDIBAPS, University of Barcelona, Barcelona, Spain.
${ }^{2}$ Medical Intensive Care Unit, Hospital Clinic, IDIBAPS, University of Barcelona, Barcelona, Spain.

${ }^{3}$ Computer System Unit, Hospital Clinic, Barcelona, Spain.

\section{ABSTRACT}

Objective. Controversial results on remdesivir efficacy have been reported. We aimed to report our real-life experience with the use of remdesivir from its availability in Spain.

Methods. We performed a descriptive study of all patients admitted for $\geq 48$ hours with confirmed COVID-19 who received remdesivir between the 1st of July and the 30th of September 2020.

Results. A total of 123 patients out of 242 admitted with COVID-19 at our hospital (50.8\%) received remdesivir. Median age was 58 years, $61 \%$ were males and $56.9 \%$ received at least one anti-inflammatory treatment. No adverse events requiring remdesivir discontinuation were reported. The need of intensive care unit admission, mechanical ventilation and 30 -days mortality were $19.5 \%, 7.3 \%$ and $4.1 \%$, respectively.

Conclusion. In our real-life experience, the use of remdesivir in hospitalized patients with COVID-19 was associated with a low mortality rate and good safety profile.

Keywords: Antivirals; COVID-19; outcome; remdesivir.

Correspondence:

Dr. Alex Soriano

Department of Infectious Diseases, Hospital Clinic of Barcelona

C/ Villarroel 170, 08036 Barcelona, Spain

Tel: (+34) 93-227-5400, ext. 2887

E-mail:asoriano@clinic.cat

${ }^{*}$ Contributed equally
Uso en vida real de remdesivir en pacientes hospitalizados con COVID-19

\section{RESUMEN}

Objetivo. Se han comunicado resultados controvertidos sobre la eficacia de remdesivir. Nuestro objetivo es comunicar nuestra experiencia en vida real con el uso de remdesivir desde su disponibilidad en España.

Métodos. Realizamos un estudio descriptivo de todos los pacientes ingresados durante $\geq 48$ horas con COVID- 19 confirmado que recibieron remdesivir entre el 1 de julio y el 30 de septiembre de 2020.

Resultados. Un total de 123 pacientes de los 242 ingresados con COVID-19 en nuestro hospital $(50,8 \%)$ recibieron remdesivir. La mediana de edad fue de 58 años, el 61\% eran varones y el $56,9 \%$ recibieron al menos un tratamiento antiinflamatorio. No se registraron acontecimientos adversos que requirieran la interrupción del remdesivir. La necesidad de ingreso en la unidad de cuidados intensivos, la ventilación mecánica y la mortalidad a los 30 días fueron del 19,5\%, el 7,3\% y el $4,1 \%$, respectivamente.

Conclusiones. En nuestra experiencia, el uso de remdesivir en pacientes hospitalizados con COVID-19 se asoció con una baja tasa de mortalidad y un buen perfil de seguridad.

Palabras clave: Antivirales; COVID-19; resultados; remdesivir 


\section{INTRODUCTION}

Severe Acute Respiratory Syndrome Coronavirus-2 (SARSCoV-2) emerged at the end of 2019, causing a devasting pandemic and reported one million deaths [1]. Initially, patients with COVID-19 received supportive care to relieve symptoms as well as antivirals according to in vitro data showing activity. However, these drugs failed to prove efficacy [2,3]. On May 1st, 2020, remdesivir received Food and Drug Administration (FDA) emergency use authorization for hospitalized patients with COVID-19 and was officially approved on October 22nd, 2020. Initial clinical trials using a control arm demonstrated the superiority of remdesivir in terms of clinical status improvement at day 28 [4] or at day 11 [5]; however, initial clinical trials performed in China [6] and a recent report from the Solidarity trial [7] did not prove that remdesivir had no benefit $[8,9]$. Different outcomes and the potential influence of when remdesivir was administered after symptom onset could explain the apparently controversial results in the aforementioned trials [10].

We aim to report our experience using remdesivir from July to September 2020, since the drug was made available in Spain.

\section{METHODS}

Study design and patients. This observational cohort study was performed at Hospital Clinic in Barcelona (Spain), a 700-bed university center that provides care for an urban population of 500,000 adults. All patients admitted for $\geq 48$ hours with COVID-19 who received remdesivir between July $15 t$ and the September 30th, 2020, were included. All patients had a COVID-19 diagnosis confirmed by real-time reverse-transcription polymerase chain reaction (rRT-PCR) performed on nasopharyngeal throat swabs. The Institutional Ethics Committee of Hospital Clinic of Barcelona approved the study and due to the nature of the retrospective data review, waived the need for informed consent from individual patients (HCB/2020/0273).

During this period, remdesivir treatment had to be approved by the Spanish Ministry of Health and dispensed by the Spanish Agency of Drugs and Health Products. Indication for remdesivir fell under consideration of attending physicians in July; however, beginning August 1st, the Spanish Agency of Drugs and Health Products established common criteria for all institutions in Spain. Criteria to prescribe remdesivir included hospitalized patients with severe pneumonia due to SARSCoV-2 documented by rRT-PCR, serology or antigen test, and all the following characteristics: 1) aged $>12$ years and $>40$ $\mathrm{kg} ; 2$ ) need of supplemental low-flow oxygen; 3 ) $\leq 7$ days from symptom onset to remdesivir prescription; and 4) met at least two of these three criteria: respiratory rate $\geq 24$ bpm, oxygen saturation at air ambient $\leq 94 \%$, or $\mathrm{PaO}_{2} / \mathrm{FiO}_{2}<300 \mathrm{mmHg}$. Exclusion criteria included requirement of supplemental highflow oxygen, mechanical ventilation, vasoactive drugs, extracorporeal membrane oxygenation (ECMO), or meeting criteria for multiorgan failure. Contraindications included aspartate amino transferase (ASAT) and alanine amino transferase (ALAT) $\geq 5$ times the normal range values, glomerular filtration $<30$ $\mathrm{mL} / \mathrm{min}$, hemodialysis, or peritoneal dialysis.

Data collection. For all patients hospitalized with COVID-19, high-quality data concerning demographics (age, sex), epidemiology, comorbidities, laboratory tests, microbiological results, treatment and outcomes were collected directly from electronic health records (EHR) using an intelligent system (SILDv1.0 system, S34M ${ }^{\circledR}$ ) as described elsewhere [11].

Statistical analysis. Qualitative variables are presented as percentages and quantitative variables as median and interquartile range (IOR).

\section{RESULTS}

We assessed 242 consecutive adults with COVID-19 at our hospital during the study period. Of these patients, 123 $(50.8 \%)$ received remdesivir. The median age was 58 years (range 48-69) and 61\% were male. Characteristics are detailed in Table 1. Remarkably, remdesivir was used in four patients with chronic kidney disease and in 24 immune-supressed patients (13 with solid neoplasm, 8 with a hematological disease and 3 with HIV infection). The median (IQR) days from symptom onset to remdesivir prescription was 7 (4-9).

Table 2 shows the treatment options and outcome. In the cohort, $56.9 \%$ of patients received at least one anti-inflammatory treatment, being the most frequent dexamethasone $(n=57)$ and/or tocilizumab $(n=33)$. Remdesivir was administered at the same time with dexamethasone in 24 patients $(24 / 57 ; 42 \%)$ and with tocilizumab in 19 (19/33; 57\%). C-reactive protein median (IOR) values at dexamethasone and tocilizumab administration were $14.3(13.6-17.4) \mathrm{mg} / \mathrm{dL}$ and 13.2 (7.8-16.1) $\mathrm{mg} / \mathrm{dL}$, respectively.

The median (IOR) baseline creatinine was $0.86 \mathrm{mg} / \mathrm{dL}$ (0.72-1.08); but 6 patients had a creatinine value of $>1.5 \mathrm{mg} /$ $\mathrm{dL}(1.52$ to $1.75 \mathrm{mg} / \mathrm{dL})$ when remdesivir was prescribed. All these patients were discharged with a creatinine value of $<1.40 \mathrm{mg} / \mathrm{dL}$ ( 0.84 to $1.40 \mathrm{mg} / \mathrm{dL}$ ). One patient, with an initial creatinine value of $1.39 \mathrm{mg} / \mathrm{dL}$, was discharged with the value at $1.72 \mathrm{mg} / \mathrm{dL}$. The median (IOR) values of ASAT and ALAT at baseline (before starting remdesivir) were 39 (24-64) U/L and 36 (23-61) U/L, respectively. The median values at hospital discharge were 33 (19-57) $\mathrm{U} / \mathrm{L}$ and 60 (35-97) $\mathrm{U} / \mathrm{L}$, respectively. The median (IOR) lymphocyte counts at baseline and at hospital discharge were $1(0.8-1.3) \times 10^{9} / \mathrm{L}$ and $1.7(1.2-2.2) \times 10^{9} / \mathrm{L}$, respectively. No adverse events requiring remdesivir discontinuation were reported.

Needs for intensive care unit (ICU) admission and mechanical ventilation was $19.5 \%$ and $7.3 \%$, respectively. The $30-$ day mortality rate was $4.1 \%(5 / 123)$, and $8.3 \%(2 / 24)$ among patients that required ICU admission. All dead patients had $\geq 80$ years and all concomitantly received any anti-inflammatory therapy. The 30-day mortality among patients receiving concomitantly remdesivir and dexamethasone was $16.7 \%$ and $5.3 \%$ with tocilizumab. 


\begin{tabular}{l|l}
\hline Table 1 & $\begin{array}{l}\text { Clinical characteristics of } 123 \\
\text { consecutive adults treated with } \\
\text { remdesivir for COVID-19. }\end{array}$ \\
\hline
\end{tabular}

\begin{tabular}{|c|c|}
\hline \multicolumn{2}{|l|}{ Patient characteristics } \\
\hline Median (IOR) age, in years & $58(48-69)$ \\
\hline Age $>65$ years $(\%)$ & $41(33.3 \%)$ \\
\hline Sex male, $n(\%)$ & $75(61 \%)$ \\
\hline \multicolumn{2}{|l|}{ Comorbidities (\%) } \\
\hline Hypertension & $50(40.7 \%)$ \\
\hline Diabetes mellitus & $27(22 \%)$ \\
\hline Chronic heart disease & $19(15.4 \%)$ \\
\hline Chronic lung disease & $24(19.5 \%)$ \\
\hline Chronic liver disease & $6(3 \%)$ \\
\hline Chronic kidney disease & $4(3.3 \%)$ \\
\hline Solid neoplasm & $13(10.6 \%)$ \\
\hline Hematological disease & $8(6.5 \%)$ \\
\hline HIV & $3(2.4 \%)$ \\
\hline Median (IQR) days from symptom onset to hospital admission & $6(4-8)$ \\
\hline Median (IOR) days from symptom onset to remdesivir & $7(4-9)$ \\
\hline \multicolumn{2}{|l|}{ Vital signs at admission } \\
\hline Median $(\mathrm{IQR})$ temperature $\left({ }^{\circ} \mathrm{C}\right)$ & $37(36.5-38)$ \\
\hline Median (IOR) respiratory rate (rpm) & $20(18-26)$ \\
\hline Respiratory rate > $20(\%)$ & $80(65 \%)$ \\
\hline Median (IOR) oxygen saturation (\%) & $94(93-95)$ \\
\hline Oxygen saturation < $94 \%(\%)$ & $48(39 \%)$ \\
\hline Median (IQR) cardiac rate (rpm) & $91(82-100)$ \\
\hline \multicolumn{2}{|l|}{ Laboratory at admission, median (IOR) } \\
\hline Ferritin (ng/mL) & 495 (287-1096) \\
\hline C-RP (mg/dL) & $7.99(4.69-14.47)$ \\
\hline D-dimer (ng/mL) & $500(300-900)$ \\
\hline LDH (U/L) & $323(265,75-376)$ \\
\hline Lymphocyte count (x109/L) & $1(0.7-1.3)$ \\
\hline Creatinine $(\mathrm{mg} / \mathrm{dL})$ & $0.86(0.72-1.08)$ \\
\hline ASAT (U/L) & 39 U/L (24-64) \\
\hline ALAT (U/L) & $36 \mathrm{U} / \mathrm{L}(23-61)$ \\
\hline
\end{tabular}

\section{DISCUSSION}

This is the first report to assess the efficacy and tolerability of remdesivir in a real-life cohort of patients with COVID-19, including those with cancer or hematological disease. Our results documented a low mortality rate $(4.1 \%)$ in hospitalized patients receiving remdesivir for severe pneumonia due to SARS-CoV-2. This rate is in line with that reported in the ACTT-1 study that randomized patients to remdesivir or placebo [4]. Our patients mainly correspond to those in the

\begin{tabular}{|c|c|c|}
\hline Table 2 & \multicolumn{2}{|c|}{$\begin{array}{l}\text { Concomitant treatment and outcomes } \\
\text { of } 123 \text { consecutive adults treated with } \\
\text { remdesivir for COVID-19. }\end{array}$} \\
\hline \multicolumn{3}{|l|}{ Treatment } \\
\hline \multicolumn{3}{|c|}{ Other drugs with potential antiviral effect } \\
\hline \multicolumn{2}{|c|}{ Lopinavir/ritonavir (\%) } & $1(0.8 \%)$ \\
\hline \multicolumn{3}{|c|}{ Anti-inflammatory effect } \\
\hline \multicolumn{2}{|c|}{ Tocilizumab (\%) } & $33(26.8 \%)$ \\
\hline \multicolumn{2}{|c|}{ Anakinra $(\%)$} & $7(5.7 \%)$ \\
\hline \multicolumn{2}{|c|}{ Methyl-prednisolone (\%) } & $14(11.4 \%)$ \\
\hline \multicolumn{2}{|c|}{ Dexamethasone $(\%)$} & $57(46.3 \%)$ \\
\hline \multicolumn{2}{|c|}{ Prednisone $(\%)$} & $24(19.5 \%)$ \\
\hline \multicolumn{3}{|c|}{ Antibiotic treatment } \\
\hline \multicolumn{2}{|c|}{ Ceftriaxone $(\%)$} & $52(42.8 \%)$ \\
\hline \multicolumn{2}{|c|}{ Ceftaroline (\%) } & $16(13 \%)$ \\
\hline \multicolumn{3}{|l|}{ Outcomes } \\
\hline \multicolumn{2}{|c|}{ Median (IOR) of length of hospital stay } & $8(6-12)$ \\
\hline \multicolumn{2}{|c|}{ ICU admission (\%) } & $24(19.5 \%)$ \\
\hline \multicolumn{2}{|c|}{ Need of mechanical ventilation $(\%)$} & $9(7.3 \%)$ \\
\hline \multicolumn{2}{|c|}{ 30-day mortality (\%) } & $5(4.1)$ \\
\hline
\end{tabular}

ACT-1 study with a baseline ordinal score of 5 (hospitalized patients requiring supplemental oxygen) who had a mortality rate of 3.8\% in the remdesivir arm versus $12.3 \%$ in the control $\mathrm{arm}$. The total number of patients in this study subgroup was 435 (232 and 203 in each arm), being the largest group. This is reasonable since this is the most common type of patients requiring hospital admission in the daily practice, therefore, our results enlarge the experience in this important subgroup.

The most severe patients required co-administration of an anti-inflammatory therapy, and as expected they had the highest mortality rate. Interestingly, the concomitant use of remdesivir and tocilizumab was associated with the lowest mortality rate in this group (5.3\%), in line with the recent report showing better outcomes among patients receiving remdesivir plus baricitinib [12]. Both inmune-modulators inhibit specific pathways of inflammatory cascade instead of the broad-spectrum inhibition induced by steroids with potential harmful consequences [13].

The optimal timing for remdesivir treatment remains to be clarified. SARS-CoV-2 shedding from the respiratory tract peaks during the first 2-3 days from clinical symptom onset and rapidly decreases [14], consistent with a brief window of clinical benefit from antiviral drugs. In this scenario, prompt initiation of antiviral treatment may be the key point to improve outcomes of patients with COVID-19. Such approach has been documented in other respiratory virus such as the influenza, with the use of neuraminidase inhibitors [15]. In our cohort, remdesivir was administered earlier than in the ACT-1 
study (median of 7 vs. 9 days from symptom onset to remdesivir) [4]. Such early drug administration could explain the shorter length of hospital stay ( 8 vs. 12 days) and lower need of mechanical ventilation (7.3 vs. 12.9\%). A prior trial [6] failed to demonstrate any benefits from remdesivir treatment in patients with COVID-19; however, the median days from symptom onset to remdesivir was 11 and, indeed, 37 of the 196 (19\%) patients had undetectable viral RNA on nasopharyngeal and oropharyngeal swabs obtained at baseline. Considering all together, this data suggests that patients included in this study were in a late stage with low viral load and, therefore, the expected benefit of an antiviral in this population is miminal.

The impact of remdesivir on reducing viral shedding has been reported in macaques [16]. Information about viral shedding in humans receiving remdesivir treatment is, however, lacking. Such information is important to define the duration of transmissibility and the potential consequences on the isolation measures.

Our cohort supports the good tolerability profile of remdesivir, presenting with no serious adverse events and, in particular, no alterations in liver enzymes. No patient required discontinuation of the drug.

The main limitation of this study was its retrospective nature and a possible underreporting of adverse events. However, we were able to closely monitor laboratory parameters to minimize this problem. However, the strength of our study is that the Spanish Ministry of Health perfectly defined the indication for remdesivir and our results support such current indication.

We conclude that the use of remdesivir in hospitalized patients with pneumonia due to SARS-CoV-2 is associated with a Iow mortality rate and has a good safety profile.

\section{AKNOWLEDGEMENTS}

\section{- We would like to thank all Hospital Clinic of Barcelona COVID-19 Researchers:}

Infectious Diseases' Research Group: Albiach L, Blanco JL, De la Mora L, Del Rio A, González-Cordón A, Inciarte A, Laguno M, Leal L, Mallolas J, Martínez E, Martínez M, Miró JM, Moreno A, Rojas J, Solá M, Torres B, Torres M, and all the staff members.

Medical Intensive Care Unit: Adrian Téllez, Sara Fernández, and all the staff members.

Department of International Health: Daniel Camprubi Ferrer, Maria Teresa de Alba, Marc Fernandez, Elisabet Ferrer, Berta Grau, Helena Marti, Laura Letona, Magdalena Muelas, Maria Jesus Pinazo, Natalia Rodríguez, Montserrat Roldan, Carme Subira, Isabel Vera, Nana Williams, Jose Muñoz, and all the staff members.

Department of Internal Medicine: Aldea A, Camafort M, Calvo J, Capdevila A, Cardellach F, Carbonell I, Coloma E, Foncillas $A$, Estruch $R$, Feliu M, Fernández-Solá J, Fuertes I, Gabara
C, Ladino A, López-Alfaro R, López-Soto A, Masanés F, Matas A, Navarro M, Marco-Hernández J, Miguel L, Milisenda J, Moreno P, Naval J, Nicolás D, Oberoi H, Padrosa J, Prieto- González S, Pellicé M, Ribot J, Rodríguez-Núnez O, Sacanella E, Sierra C, Tomé $A$, Ugarte $A$, Ventosa $H$, Zamora-Martinez $C$, and all the staff members.

Department of Microbiology: M. Almela, M. Alvarez, J. Bosch, C. Casals, J. Costa, G. Cuesta, M. Fernandez, B. Fidalgo, J. Gonzàlez, J.C. Hurtado, F. Marco, M.A. Marcos, M. Martínez, M. Mosquera, S. Narvaez, C. Pitart, E. Rubio, A. Vergara, M.E.Valls, J. Vila, Y. Zboromyrska and all the staff members.

Department of Farmacy: E. López, D. Soy, M. Tuset and all the staff members.

- We would like to thank Anthony Armenta for providing medical editing assistance

\section{FUNDING}

This work has received a grant from a crowdfunding organised by Hospital Clínic and IDIBAPS. Gilead provided medical writing support but was not involved in the content of the manuscript.

\section{CONFLICT OF INTERESTS}

CGV has received honoraria for talks on behalf of Gilead Science, MSD, Novartis, Pfizer, Janssen, and Lilly, as well as a grant from Gilead Science and MSD. PPA has received honoraria for talks on behalf of Gilead Science and MSD. PC has received honoraria for talks on behalf of Gilead Science, MSD, Pfizer, Janssen, Kite and Alexion. JM has received honoraria for talks on behalf of MSD, Pfizer, Novartis, and Angellini. AS has received honoraria for talks on behalf of MSD, Pfizer, Novartis, Shionogi, Gilead Science and Angellini, as well as grant support from Pfizer and Gilead Science. Other authors do not declare conflict of interest.

\section{REFERENCES}

1. World Healthy Organization. Clinical management of severe acute respiratory infection when COVID-19 is suspected (v1.2). Who. 2020;1-21. Available from: https://www.who.int/publications-detail/clinical-management-of-severe-acute-respiratory-infection-when-novel-coronavirus-(ncov)-infection-is-suspected

2. RECOVERY Collaborative Group Effect of Hydroxychloroquine in Hospitalized Patients with Covid-19. N Engl J Med. 2020;383(21):2030-2040. doi: 10.1056/NEJMoa2022926.

3. Cao B, Wang Y, Wen D, Liu W, Wang J, Fan G, et al. A Trial of Lopinavir-Ritonavir in Adults Hospitalized with Severe Covid-19. N Engl J Med. 2020;382(19):1787-1799. doi: 10.1056/NEJMoa2001282.

4. Beigel JH, Tomashek KM, Dodd LE, Mehta AK, Zingman BS, Kalil $A C$, et al. Remdesivir for the Treatment of Covid-19 - Final Report. N Engl J Med. 2020;383(19):1813-1826. doi: 10.1056/NEJMoa2007764. 
5. Spinner CD, Gottlieb RL, Criner GJ, Arribas López JR, Cattelan AM, Soriano Viladomiu A, et al. Effect of Remdesivir vs Standard Care on Clinical Status at 11 Days in Patients With Moderate COVID-19: A Randomized Clinical Trial. JAMA. 2020;324(11):1048-1057. doi: 10.1001/jama.2020.16349.

6. Wang Y, Zhang D, Du G, Du R, Zhao J, Jin Y, et al. Remdesivir in adults with severe COVID-19: a randomised, double-blind, placebo-controlled, multicentre trial. Lancet. 2020 May 16;395(10236):1569-1578. doi: 10.1016/S0140-6736(20)31022-9.

7. WHO Solidarity Trial Consortium, Pan H, Peto R, Henao-Restrepo A-M, Preziosi M-P, Sathiyamoorthy V, et al. Repurposed Antiviral Drugs for Covid-19 - Interim WHO Solidarity Trial Results. N Engl J Med. 2021;384(6):497-511. doi: 10.1056/NEJMoa2023184. 6

8. Rochwerg B, Agarwal A, Zeng L, Leo YS, Appiah JA, Agoritsas T, et al. Remdesivir for severe covid-19: a clinical practice guideline. BMJ. 2020;370:m2924. doi: 10.1136/bmj.m2924.

9. Siemieniuk $R$, Rochwerg $B$, Lamontagne $F$, Agoritsas $T$, MacDonald $H$, Leo YS, et al. A living WHO guideline on drugs for covid-19. BMJ. 2020;370:m3379. doi: 10.1136/bmj.m3379.

10. Young $B$, Tan $\Pi$, Leo YS. The place for remdesivir in COVID-19 treatment. Lancet Infect Dis. 2021;21(1):20-21. doi: 10.1016/ S1473-3099(20)30911-7

11. Garcia-Vidal C, Sanjuan G, Puerta-Alcalde P, Moreno-García E, Soriano A. Artificial intelligence to support clinical decision-making processes. EBioMedicine. 2019;46:27-29. doi: 10.1016/j.ebiom.2019.07.019.

12. Kalil AC, Patterson TF, Mehta AK, Tomashek KM, Wolfe CR, Ghaz-

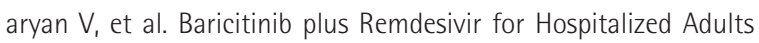
with Covid-19. N Engl J Med. 2020 Dec 11:NEJMoa2031994. doi: 10.1056/NEJMoa2031994.

13. Yao T-C, Huang Y-W, Chang S-M, Tsai S-Y, Wu AC, Tsai H-J. Association Between Oral Corticosteroid Bursts and Severe Adverse Events : A Nationwide Population-Based Cohort Study. Ann Intern Med. 2020;173(5):325-330. doi: 10.7326/M20-0432.

14. Rhee $C$, Kanjilal S, Baker M, Klompas M. Duration of Severe Acute Respiratory Syndrome Coronavirus 2 (SARS-CoV-2) Infectivity: When Is It Safe to Discontinue Isolation? Clin Infect Dis. 2020 Aug 25:ciaa1249. doi: 10.1093/cid/ciaa1249.

15. Louie JK, Yang S, Acosta M, Yen C, Samuel MC, Schechter R, et al. Treatment with neuraminidase inhibitors for critically ill patients with influenza A (H1N1)pdm09. Clin Infect Dis. 2012;55(9):1198204. doi: $10.1093 /$ cid/cis636.

16. Williamson BN, Feldmann F, Schwarz B, Meade-White K, Porter DP, Schulz J, et al. Clinical benefit of remdesivir in rhesus macaques infected with SARS-CoV-2. Nature. 2020;585(7824):273-276. doi: 10.1038/s41586-020-2423-5. 